\title{
Antibodies against 4-hydroxy-2-nonenal modified epitopes recognized chromatin and its oxidized forms: Role of chromatin, oxidized forms of chromatin and 4-hydroxy-2-nonenal modified epitopes in the etiopathogenesis of SLE
}

\author{
Hani A. Al-Shobaili ${ }^{\mathrm{a}}$, Ahmad A. Al Robaee ${ }^{\mathrm{a}}$, Abdullateef A. Alzolibani ${ }^{\mathrm{a}}$ and Zafar Rasheed ${ }^{\mathrm{b}, *}$ \\ ${ }^{a}$ Department of Dermatology, College of Medicine, Qassim University, Buraidah, KSA \\ ${ }^{\mathrm{b}}$ Department of Medical Biochemistry, College of Medicine, Qassim University, Buraidah, KSA
}

\begin{abstract}
Objectives: This study was undertaken to investigate the role of lipid oxidative-by-product 4-hydroxy-2-nonenal (HNE)-modified human serum albumin (HSA), chromatin, reactive oxygen species (ROS)-modified chromatin and nitric oxide (NO)-modified chromatin in systemic lupus erythematosus (SLE).

Methods: HSA was modified by HNE. Immunogenicity of modified HSA was probed by inducing polyclonal antibodies in rabbits. Chromatin was isolated from goat liver and modified by ROS or NO. Immunocross-reactions of Protein-A purified antiHNE-HSA-IgG with chromatin, ROS-chromatin and NO-chromatin were determined. Autoantibodies from 74 SLE patients were screened. HSA was isolated from SLE patients (SLE-HSA) and immunocross-reactions of isolated SLE-HSA with HNE-specific antibodies were investigated.

Results: HNE-HSA was found to be highly immunogenic in rabbits. The notable feature of anti-HNE-HSA-IgG showed cross-reactions with chromatin, ROS-chromatin and NO-chromatin $(p<0.01)$. High degree of specific binding to HNEHSA, chromatin, ROS-chromatin or NO-chromatin was observed with antibodies from 55\% of SLE patients. SLE anti-native/ oxidized chromatin antibodies showed specificity towards HNE-HSA. Furthermore, SLE-HSA showed binding with HNE-specific antibodies.

Conclusions: This is the first study to demonstrate that chromatin and its oxidized forms have been recognized by antibodies against HNE modified epitopes. Our results provide an important insight into the immunological basis of the reported HNE-modified epitopes in SLE.
\end{abstract}

Keywords: Systemic lupus erythematosus, autoimmunity, 4-hydroxy-2-nonenal, chromatin, free radicals

\section{Introduction}

4-Hydroxy-2-nonenal (HNE) is one of the most prominent lipid peroxidation-specific aldehydes, is be-

*Corresponding author: Zafar Rasheed, Department of Medical Biochemistry, College of Medicine, Qassim University, P.O. Box 6655, Buraidah-51452, KSA. Tel.: +966 531269227; E-mail: zafarrasheed@ rocketmail.com. lieved to be largely responsible for the pathological effects observed during oxidative stress [1]. HNE exerts these effects because of its facile reactivity with biological materials, including proteins [2]. It is reported that the sequence of an anti-HNE monoclonal antibodies (mAb) has highly homologous to the antiDNA autoantibodies [3]. Excess generation of reactive oxygen species (ROS) have the ability, either directly or indirectly, to damage proteins, DNA, lipids 
and other cell biomolecules [4,5]. Protein oxidation, which results in functional disruption, is not random but appears to be associated with increased oxidation in specific proteins [5]. Human serum albumin (HSA) is the most abundant serum protein whose redox modification modulates its physiologic function, as well as serves as biomarker of oxidative stress [6,7]. Therefore, HSA is continuously exposed to oxidative stress, so that alterations of the conformation and function of HSA could occur, resulting in the modification of its biological properties.

Systemic lupus erythematosus (SLE) is a multifactorial autoimmune disease with several clinical manifestations [8,9]. The initial immunizing immunogen (s) that drive the development of SLE are unknown, but it was accepted that intermolecular epitope spreading was one of the mechanisms for the amplification and diversification of autoantibody responses in SLE [10]. Anti-double stranded DNA (anti-dsDNA) autoantibodies are a prime feature of SLE [9]. However, evidence has accumulated in recent years that anti-chromatin autoantibodies are correlated even better with SLE than anti-dsDNA autoantibodies $[11,12]$ and anti-chromatin antibodies are known to occur in SLE before the appearance of anti-dsDNA antibodies [10]. Studies have shown that $65 \%$ of anti-DNA negative SLE patients are anti-chromatin antibody positive [12].

In the present study, commercially available HSA was modified by lipid oxidation product HNE. Immunization of rabbits with either HNE-modified HSA (HNE-HSA) or native HSA (nHSA) and an antibody response was established faster and more vigorously in the animals that were immunized with the HNEHSA. Chromatin was isolated from goat liver and modified by ROS or nitric oxide (NO). Cross-reactions of affinity purified anti-ROS-HSA IgG or anti-nHSA IgG with chromatin, ROS-modified chromatin, NOmodified chromatin were determined and found that anti-ROS-HSA IgG showed immunospecificity with chromatin and its oxidized forms. This is our novel finding and has not been reported previously. In addition, the antigen(s) binding characteristics of naturally occurring SLE autoantibodies to HNE-HSA, nHSA, ROS-chromatin, NO-chromatin and unmodified chromatin were evaluated. Antibodies against chromatin, ROS-chromatin and NO-chromatin from SLE patients were also tested for the recognition of in-vitro generated HNE-HSA. Furthermore, immunocross-reactions of induced anti-HNE-HSA IgG and anti-nHSA IgG with HSA from SLE patients (SLE-HSA) and HSA from normal human controls (NH-HSA) were also attempted.

\section{Materials and methods}

\subsection{Preparation of protein-HNE antigen}

4-Hydroxy-2-nonenol (HNE; Cayman Scientific, Ann Arbor, MI, USA) modified protein (protein-HNE) antigen was prepared in Tris-HCl buffer as previously described [13]. Briefly HSA (Sigma-Aldrich, Co, USA) (1 mg) was incubated with Tris- $\mathrm{HCl}(5 \mathrm{mM}, \mathrm{pH}$ 8.3), and $\mathrm{HNE}(5 \mathrm{mM})$ for $7 \mathrm{~h}$ at $37^{\circ} \mathrm{C}$. The unbound HNE was removed by centrifuging the sample with a 10,000-molecular-weight cut-off spin microfuge from Millipore (MA, USA). Generation of HNE in the reaction mixture was confirmed by L-carnosine (catalog \# C9625, Sigma-Aldrich, CO, USA), a well known HNE inhibitor [14]. Concentration of L-carnosine in the reaction mixture was $20 \mathrm{mM}$.

\subsection{Immunization schedule}

The immunization of random bred, New Zealand white female rabbits $(2-2.5 \mathrm{~kg})$ was performed as described previously with some modifications [15]. Rabbits ( $n=4$; two each for native and HNE-modified HSA antigens) were immunized intramuscularly at multiple sites with $50 \mu \mathrm{g}$ of antigen, emulsified with an equal volume of Freund's complete adjuvant. The animals were boosted in Freund's incomplete adjuvant at weekly intervals for 6 weeks with the same amount of antigen. Test bleeds were performed 7 days post boost, which gave an appropriate titre of the antibody. The animals were bled and the sera were separated and heated at $56^{\circ} \mathrm{C}$ for $30 \mathrm{~min}$ to inactivate complement proteins and stored at $-80^{\circ} \mathrm{C}$. Pre-immune serum samples were collected prior to immunization.

\subsection{Isolation and modification of chromatin}

Chromatin was isolated from fresh goat liver as described by Bonner et al. [16]. Briefly, $10 \mathrm{~g}$ of goat liver was homogenized with $200 \mathrm{ml}$ of saline-EDTA $(75 \mathrm{mM}$ $\mathrm{NaCl}$, and $24 \mathrm{mM}$ EDTA, $\mathrm{pH}$ 8.0). The homogenate was strained through 6-8 layer of cheese cloth. The filtrate was centrifuged at $1500 \mathrm{~g}$ for $15 \mathrm{~min}$. the pellet was homogenized in $40 \mathrm{ml}$ of Tris buffer $(50 \mathrm{mM}$, $\mathrm{pH} 8.0$ ) and sedimented at $10,000 \mathrm{~g}$ for $15 \mathrm{~min}$. This step was repeated once. The final pellet was suspended in $30 \mathrm{ml}$ of Tris buffer $(50 \mathrm{mM}, \mathrm{pH} 8.0)$. Five milliliter aliquots of the above suspension were layered on $25 \mathrm{ml}$ portions of $1.7 \mathrm{M}$ sucrose (in $10 \mathrm{mM}$ Tris buffer, $\mathrm{pH}$ 8.0) contained in centrifuge tubes. The upper two thirds 
of each tube were gently mixed and the tubes were then centrifuged at $21,000 \mathrm{rpm}$ for $3 \mathrm{~h}$ at $4^{\circ} \mathrm{C}$. The pellets were suspended in $10 \mathrm{mM}$ Tris buffer, $\mathrm{pH} 8.0$, and dialyzed overnight against the same buffer. The dialyzed suspension was sheared in Viritis homogenizer for $90 \mathrm{~s}$, stirred for $30 \mathrm{~min}$ and then centrifuged at 10,000 $\mathrm{g}$ for $30 \mathrm{~min}$. The supernatant of the above was referred to as sheared liver chromatin.

Isolated chromatin was modified by hydroxyl radicals (ROS), generated by UV irradiation (254 nm) of hydrogen peroxide $(15.1 \mu \mathrm{M})$ for $1 \mathrm{~h}$ at room temperature in PBS as described previously [17]. Excess of hydrogen peroxide was removed by extensive dialysis against PBS, $\mathrm{pH}$ 7.4. Chromatin was nitrated according to Ohshima et al. [18]. The $\mathrm{pH}$ of the solution was adjusted to 3.5 with acetic acid. Sodium nitrite $(200 \mathrm{mM})$ was added to the final concentration of $1 \mathrm{mM}$ and the solution was incubated at $37^{\circ} \mathrm{C}$ for $24 \mathrm{~h}$. Excess sodium nitrite was removed by extensive dialysis against PBS, pH 9.0. Generation of hydroxyl radicals or nitric oxide was further checked by the addition of specific inhibitor of hydroxyl radicals (D-Mannitol, catalog \# M9546, Sigma-Aldrich, CO, USA) [19] or nitric oxide (Carboxy-PTIO, catalog \# C221, Sigma-Aldrich, CO, USA) [20] in their reaction mixtures. The concentration of D-Mannitol and Carboxyl-PTIO used in their specific reactions were $286 \mathrm{mM}$ and $30 \mathrm{mM}$, respectively.

\subsection{Assay of carbonyl formation}

Carbonyls contents of native and HNE-modified HSA, chromatin and its oxidized forms of chromatin were analyzed as previously described [6]. Briefly, the reaction mixture containing $15 \mu \mathrm{M}$ of native and modified samples, $0.5 \mathrm{ml}$ of $10 \mathrm{mM} \mathrm{2,} \mathrm{4-dinitropheny-}$ lhydrazine (DNPH)/2.5 M HCl was added and thoroughly mixed. After addition of $250 \mu \mathrm{M}$ TCA (20\%) and centrifugation, the pellet was collected and washed three times with $1 \mathrm{ml}$ ethanol: ethylacetate $(1: 1) \mathrm{mix}-$ ture. The pellet was then dissolved in $1 \mathrm{ml}$ of $6 \mathrm{M}$ guanidine solution and incubated at $30^{\circ} \mathrm{C}$ for $15 \mathrm{~min}$. After centrifugation, the supernatant was collected and the carbonyl contents were estimated from the absorbance at $370 \mathrm{~nm}$ using a molar absorption coefficient of $22,000 \mathrm{M}^{-1} \mathrm{~cm}^{1}$. Samples were spectrophotometrically analyzed against a blank of $1 \mathrm{ml}$ of guanidine solution (6M). Protein concentration was determined in the samples and carbonyl contents were expressed as $\mathrm{nmol} / \mathrm{mg}$ protein.

\subsection{Patients and serum preparation}

Present study has been carried out in accordance with the Code of Ethics of the World Medical Association (Declaration of Helsinki) for humans and EC Directive 86/609/EEC for animals. The study group included 74 patients ( 69 female and 5 male) with SLE, as defined by the American College of Rheumatology 1997 revised criteria [21], and the age range was 29-67 years (mean $\pm \mathrm{SD} 49.4 \pm 12.2$ years). All SLE samples showing high titre anti-DNA antibodies $(>1: 12,800)$. No patient had an active infection, known malignancy, tuberculosis, pregnancy, or cirrhosis. The patients were informed beforehand written consents were collected. The control group comprised 35 healthy subjects (33 female and 2 male, age range $26-68$ years, mean \pm SD age $42.3 \pm 17.8$ years). The mean ages were not significantly different between the groups. The racial/ethnic and sex compositions of the SLE groups were comparable with those of the control group. Venous blood samples from the control subjects and SLE patients were collected, and the serum from individual subjects was stored in small aliquots at $-80^{\circ} \mathrm{C}$ until analyzed further.

\subsection{ELISA}

An enzyme-linked immunosorbent assay (ELISA) was performed on flat bottom 96-well, polystyrene immunoplates (NUNC, Denmark) as described previously [7]. Briefly, polystryrene polysorp immunoplates were coated with $100 \mu \mathrm{l}$ of native or HNEmodified HSA $(10 \mu \mathrm{g} / \mathrm{ml})$ in carbonate-bicarbonate buffer (0.05 M, pH 9.6). The plates were coated for $2 \mathrm{~h}$ at $37^{\circ} \mathrm{C}$ and overnight at $4^{\circ} \mathrm{C}$. Each sample was coated in duplicate and half of the plates served as control devoid of only antigen coating. Unbound antigen was washed thrice with TBS-T $(20 \mathrm{mM}$ Tris, $150 \mathrm{mM}$ $\mathrm{NaCl}$, pH 7.4 containing $0.05 \%$ Tween-20) and unoccupied sites were blocked with $2 \%$ fat free milk in TBS (10 mM Tris, $150 \mathrm{mMNaCl}, \mathrm{pH} 7.4$ ) for $4-6 \mathrm{~h}$ at $37^{\circ} \mathrm{C}$. After incubation, the plates were washed four times with TBS-T. The test serum (1:100 or serially diluted) in TBS-T or affinity purified IgG in TBS (100 $\mu \mathrm{l} /$ well $)$ was adsorbed for $2 \mathrm{~h}$ at $37^{\circ} \mathrm{C}$ and overnight at $4^{\circ} \mathrm{C}$. Bound antibodies were assayed with anti-rabbit/human alkaline phosphatase conjugate (Sigma-Aldrich, Co, USA) using p-nitrophenyl phosphate as substrate. The absorbance of each well was monitored at $410 \mathrm{~nm}$ on an automatic microplate reader (Anthos Zenyth 3100 Multimode Detectors, Salzburg, Austria). Each sam- 
ple was run in duplicate. The control wells were treated similarly but were devoid of antigen. Results were expressed as a mean of $\mathrm{A}_{\text {test }}-\mathrm{A}_{\text {control }}$.

\subsection{In-vitro modification of solid phase protein by HNE}

In-vitro modification of solid phase HSA by HNE was performed as described previously with slight modifications [22]. Briefly, HSA was coated at room temperature for $2 \mathrm{~h}$ on ELISA plates in carbonate coating buffer, the plates were washed twice with PBS, pH 7.4 and were tapped dry and HNE ( $5 \mathrm{mM})$ in PBS was added per test well. Each sample was coated in duplicate and half of the plates served as control which contained PBS, pH 7.4 alone. The plates were incubated at room temperature in a humid chamber for $4 \mathrm{~h}$ and were washed with TBS-T. The remaining steps were the same as in direct binding ELISA.

\subsection{Competitive inhibition ELISA}

Antibody specificity was determined by competitive binding assays as previously described [23,24]. Varying concentrations of inhibitors $(0-20 \mu \mathrm{g} / \mathrm{ml})$ were allowed to interact with a constant amount of antiserum or affinity purified $\mathrm{IgG}$ for $2 \mathrm{~h}$ at $37^{\circ} \mathrm{C}$ and overnight at $4^{\circ} \mathrm{C}$. The immune complex thus formed was coated in the wells instead of serum/IgG. The remaining steps were the same as in direct binding ELISA. Percent inhibition was calculated using the formula:

Percent inhibition $=1-\left[\left(\mathrm{A}_{\text {inhibited }} / \mathrm{A}_{\text {uninhibited }}\right)\right]$ $\times 100$

\subsection{Purification of immunoglobulin $G$}

IgG from rabbit/human sera was isolated by affinity chromatography using Protein A-Sepharose CL-4B column (Sigma-Aldrich, Co, USA) as described previously [25]. Serum $(0.3 \mathrm{ml})$ diluted with equal volume of PBS, pH 7.4 was applied to the column (12 $\mathrm{mm} \times$ $45 \mathrm{~mm}$ ) equilibrated with the same buffer. The flow through was reloaded onto the column 2-3 times. Unbound proteins were removed by extensive washing with PBS, pH 7.4. The bound IgG was eluted with $0.58 \%$ acetic acid in $0.85 \%$ sodium chloride and neutralized with $1.0 \mathrm{ml}$ of $1.0 \mathrm{~mol} / \mathrm{l}$ Tris- $\mathrm{HCl}, \mathrm{pH} 8.5$, $1 \mathrm{ml}$ fractions were collected and read at 251 and $278 \mathrm{~nm}$. The IgG concentration was determined considering $1.38 \mathrm{OD}_{278}=1.0 \mathrm{mg} \mathrm{IgG} / \mathrm{ml}$. The isolated IgG was dialyzed against PBS, $\mathrm{pH} 7.4$ and stored at $-20^{\circ} \mathrm{C}$. The homogeneity of isolated IgG was checked by polyacrylamide gel electrophoresis.

\subsection{Immunoprecipitation}

Affinity purified SLE IgG $(200 \mu \mathrm{g})$ was incubated with $200 \mu \mathrm{g}$ of chromatin, ROS-chromatin, or NO-chromatin in different reaction tubes with gentle rocking overnight at $4{ }^{\circ} \mathrm{C}$. Protein $\mathrm{A} / \mathrm{G}$ agarose beads (Pierce, Rockford, IL, USA) were added (40 $\mu \mathrm{l}$ of $50 \%$ bead slurry in $500 \mu \mathrm{l}$ of total reaction volume) and incubated with gentle rocking for 3 hours at $4^{\circ} \mathrm{C}$. Microcentrifuged the reaction tubes for 30 seconds at $4^{\circ} \mathrm{C}$ and washed the pellets five times with $500 \mu \mathrm{l}$ of PBS, $\mathrm{pH}$ 7.4. After the final wash, supernatant was removed. Desired SLE antibodies were eluted from the solid support using low-pH and analyzed with direct binding ELISA by in-vitro modification of solid phase HSA by HNE as described previously [22].

\subsection{Purification of HSA from SLE patients and normal healthy controls}

Albumin was isolated by ammonium sulphate fractionation followed by gel exclusion chromatography on Sephacryl S-200 HR column as previously described [26]. Protein in each fraction was monitored by the method of Lowry et al. [27]. The purity of the isolated HSA was checked by SDS-PAGE.

\subsection{Western immunoblot analysis}

Immunoblot of antibodies from SLE and normal human $(\mathrm{NH})$ serum samples binding to HNE-modified HSA or unmodified HSA as described previously [28]. HNE-HSA or nHSA ( $40 \mu \mathrm{g})$ was resolved on $4 \%-20 \%$ gradient SDS-PAGE (Bio-Rad) and PVDF immobilonP transfer membranes (Millipore Corporation, Bedford, MA, USA). The membrane was then excised into strips and each membrane strip was blocked with non-fat dry milk powder in Tris buffered saline and $0.1 \%$ Tween20 (TBS-T). Each strip was probed with a different serum samples diluted 1:100. Immunoreactive blot strips were visualized by using 1:1000 diluted HRPlinked secondary antibodies and enhanced chemiluminescence (GE Healthcare, Milwaukee, WI, USA). Images were captured using AFP-Imaging System (Minimedical Series, Elms Ford, NY, USA).

\subsection{Statistical analysis}

All measurements were performed in duplicates and repeated at least 3 times using age- and sex-matched 


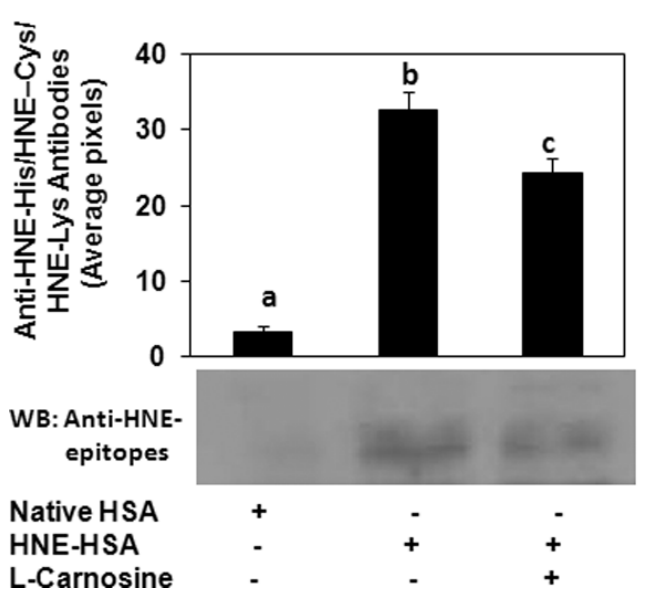

(a)

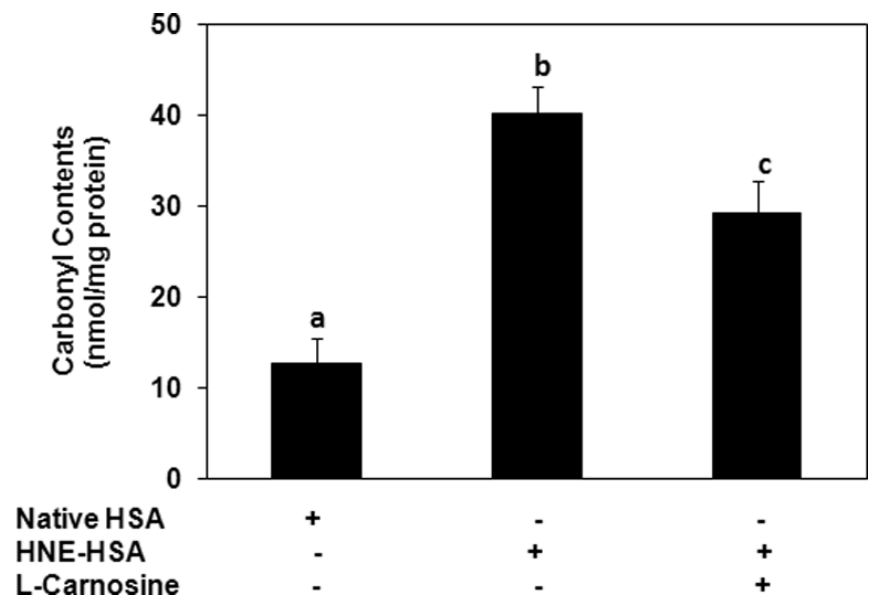

(b)

Fig. 1. Characterization of 4-hydroxy-2-nonenal (HNE) modification of human serum albumin (HSA). (a) Immunoblot analysis of HNE-modification of HSA. Native HSA, HNE-modified HSA and HNE-HSA in the presence of L-Carnosine were immunoblotted with anti-HNE-monoclonal antibodies. These monoclonal antibodies were specific for 4HNE-lysine, 4HNE-histidine and 4HNE-cysteine adduct. Band images were digitally captured and the band intensities (pixels/band) were obtained using the Un-Scan-It software. Average pixel values presented as Mean \pm SD; data without a common letter differ, $p<0.05$. (b) Carbonyl contents in native HSA, HNE-HSA and HNE-HSA in the presence of L-Carnosine. The protein concentration in all samples was $15 \mu \mathrm{M}$. Each histogram represents the mean $\pm \mathrm{SD}$ of five independent assays. Data without a common letter differ, $p<0.01$.

SLE or control samples. Comparisons were performed using Origin 6.1 software package (Northampton, MA, USA) and Graph Pad Prism-5 (San Diego, CA, USA) (one paired two tailed $t$-test with ANOVA analysis and Tukey's post-hoc analysis). $P$ values less than 0.05 were considered significant, and $P$ values less than 0.001 were considered highly significant. Values shown are mean \pm SEM unless stated otherwise.

\section{Results}

\subsection{Characterization of HNE-modified HSA}

Earlier reports [29-31] showed alterations in HSA following exposure to the HNE. HPLC analysis showed that HNE was rapidly quenched by HSA because of the covalent adduction to the different accessible nucleophilic residue of the protein, as demonstrated by electrospay ionization mass spectrometry (ESI-MS) [29]. A liquid chromatography-tanden mass spectrometry (LC-MS) analysis identified 11 different HNE-adducts, 8 Michael adducts and 3 Schiff bases and it was found that HNE forms stable protein adducts with histidine, lysine and cystein side chain [29,30]. Lipid peroxidation generated epitopes on HSA was further characterized by Western immunoblot analysis using commercially available HNE-specific monoclonal antibod- ies (JalCA, Shizuoka, Japan). These antibodies were specific for 4HNE-lysine, 4HNE-histidine or 4HNEcysteine adduct. Our results clearly showed that invitro generated HNE-HSA was well recognized by anti-HNE-His/lys/cys antibodies. The generation of HNE was further confirmed by using L-Carnosine, well known quenchers of HNE-products. The data showed a significant loss $(p<0.05)$ in the band intensity, when the modification was done in the presence of LCarnosine, whereas band intensity was high in the absence of this quencher (Fig. 1a). Carbonyl contents estimation in native HSA, HNE-HSA and HNE-HSA with L-Carnosine further reiterate the Western immunobloting results (Fig. 1). The data showed a significant increase $(p<0.001)$ in carbonyl formation in HNE-HSA as compared with unmodified HSA. Addition of LCarnosine to the reaction mixture significantly decrease $(p<0.05)$ the carbonyl contents (Fig. 1b).

\subsection{Antigenicity of HNE-modified epitopes}

Immunizations of HNE-modified HSA adduct or unmodified HSA in rabbits induced high titre antibodies. HNE-modified HSA was found to be a potent immunogen in rabbits inducing high titre antibodies (titre $=51200$ ), whereas with native HSA the titre was low (titre $=25600$ ) under identical experimental conditions (Fig. 2a). Preimmune serum serve as negative con- 


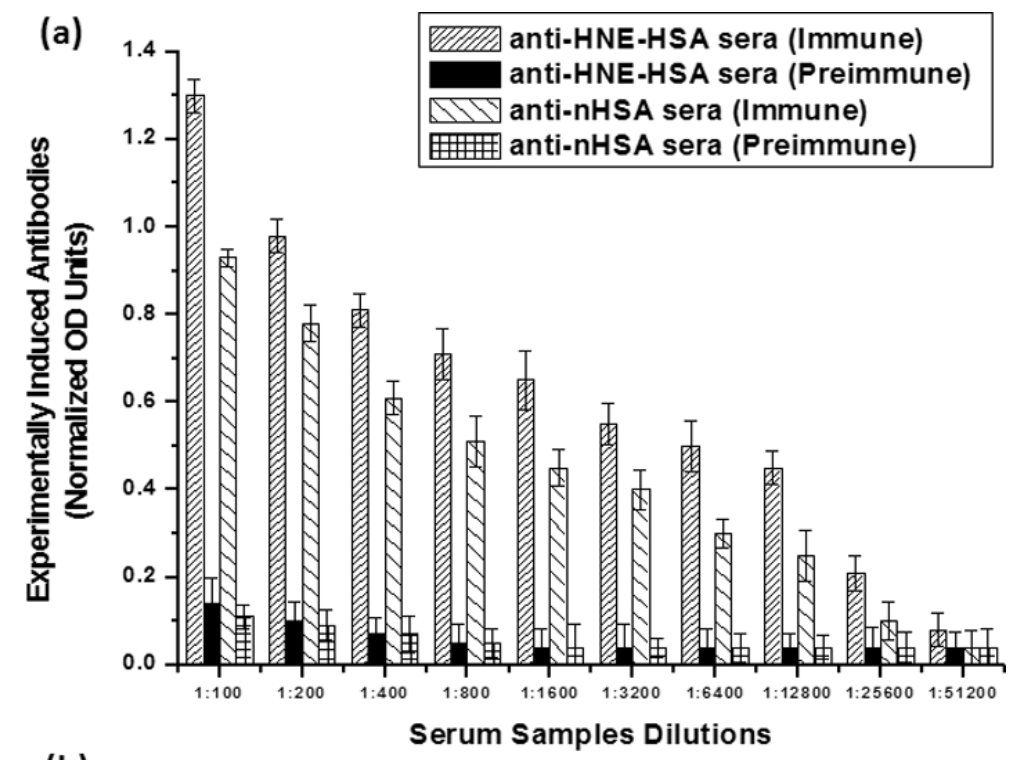

(b)

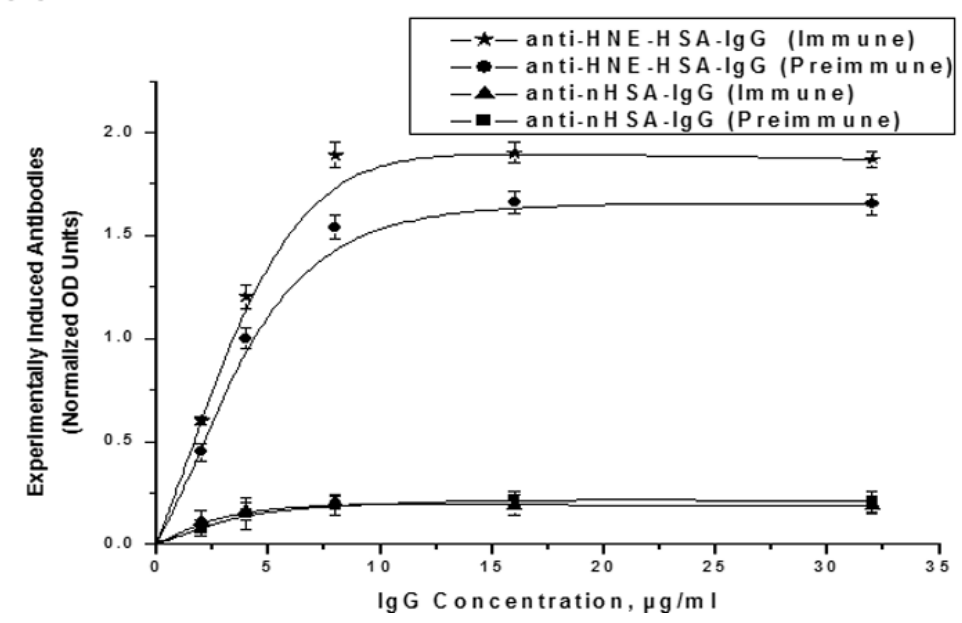

Fig. 2. Level of experimentally induced antibodies against 4-hydroxy-2-nonenal-modified human serum albumin (HNE-HSA) and native human serum albumin (nHSA). (a) Binding of HNE-HSA or nHSA with their respective immune and preimmune sera. (b) Binding of HNE-HSA or nHSA with their respective immune and preimmune affinity purified IgG. New Zealand white rabbits $(n=4$; two each for HNE-HSA or nHSA antigens) were immunized intramuscularly as described in methods. Microtitre plates were coated with their respective antigens $(10 \mu \mathrm{g} / \mathrm{ml})$. Each point represents a mean \pm SEM of four independent assays.

trol, showed negligible binding with modified or unmodified proteins. Direct binding ELISA of Protein ASepharose isolated anti-HNE-HSA IgG and anti-nHSA IgG showed strong binding with their respective immunogens. Preimmune affinity purified IgG showed negligible binding under identical conditions (Fig. 2b).

\subsection{Characterization of ROS-modified and NO-modified chromatin}

Modifications in chromatin by ROS or NO have been studied by carbonyl contents estimation. The average carbonyl contents ( \pm SD) of five independent assays in unmodified chromatin were $18.4 \pm 3.3 \mathrm{nmol} / \mathrm{mg}$ protein. Whereas, the carbonyl contents $( \pm$ SD) of five independent assays in ROS and NO-modified chromatin were $53.6 \pm 3.3$ and $49.5 \pm 3.8 \mathrm{nmol} / \mathrm{mg}$ protein, respectively (Fig. 3), a p-value of $<0.001$ indicates significant difference in the carbonyl contents of native and modified chromatin. The generation of hydroxyl radicals in ROS modification of chromatin was confirmed by using D-mannitol, specific inhibitor of hydroxyl radicals. The data showed significant decreased $(p<0.05)$ in carbonyl formation, when the modifica- 


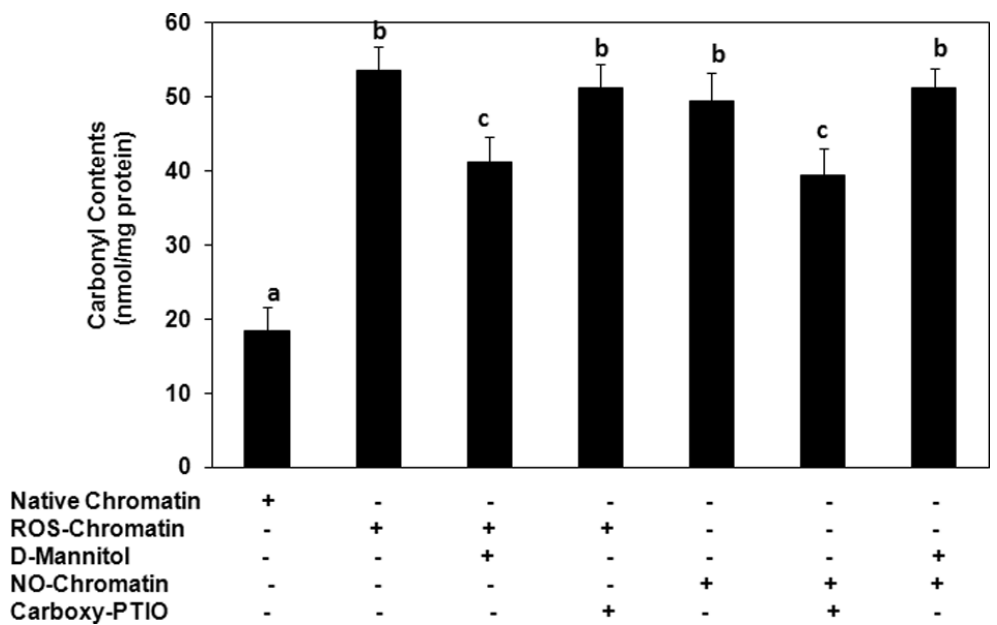

Fig. 3. Modification of chromatin by reactive oxygen species and nitric oxide. Carbonyl contents in native chromatin, reactive oxygen speciesmodified chromatin (ROS-chromatin), ROS-chromatin in the presence of D-mannitol (catalog \# M9546, Sigma-Aldrich) or carboxyl-PTIO (catalog \# C221, Sigma-Aldrich), nitric oxide-modified chromatin (NO-chromatin) and NO-chromatin in the presence of carboxyl-PTIO or D-mannitol. The protein concentration in all samples was $15 \mu \mathrm{M}$. Each histogram represents the mean \pm SEM of five independent assays. Data without a common letter differ, $p<0.01$.

tion was done in the presence of this inhibitor. Whereas, high carbonyl formation occurred in its absence (Fig. 3). Similarly, generation of nitric oxide was also confirmed by using NO inhibitor, Carboxy-PTIO. Carbonyl formation was significantly decreased $(p<$ $0.05)$, when NO modification was done in the presence of this inhibitor (Fig. 3). We also cross checked the effect of NO inhibitor on the generation of hydroxyl radicals or hydroxyl radicals inhibitor on NO generation. The data showed D-mannitol had no effect on the generation of NO. Likewise, Carboxyl-PTIO was also failed to inhibit the generation of hydroxyl radicals (Fig. 3).

\subsection{Recognition of chromatin, ROS-modified chromatin and NO-modified chromatin by anti-HNE-protein antibodies}

Induced IgG against HNE-modified HSA or unmodified HSA was purified by affinity chromatography on Protein A-Sepharose CL-4B column. The purified IgG was found to elute in a single symmetrical peak and migrated as a single homogenous band on SDS-PAGE (data not shown). Affinity purified anti-HNE-HSA IgG and anti-nHSA IgG were tested for binding to native or oxidized chromatins by direct binding ELISAs. Our data showed that chromatin, ROS-chromatin and NOchromatin were well recognized by anti-HNE-HSA $\mathrm{IgG}$, but the recognition was more with ROS-chromatin or NO-chromatin (Fig. $4 \mathrm{a} ; p<0.05$ ). Whereas, anti-
nHSA IgG showed no binding with chromatin and its oxidized forms (Fig. 4b; $p>0.05$ ). Native and HNEmodified HSA showed strong binding with their respective induced antibodies and were used as positive controls in their respective binding assays (Fig. 4a\&b).

The antigenic specificity of induced anti-HNE-HSA antibodies was further characterized by competitive inhibition assays (Fig. 4c). A maximum of $97.8 \%$ inhibition of the anti-HNE-HSA IgG with the immunogen as inhibitor was observed at $20 \mu \mathrm{g} / \mathrm{ml}$ of inhibitor concentration. The anti-HNE-HSA antibodies exhibited a variable recognition of chromatin, ROS-modified chromatin and NO-modified chromatin in competition ELISA. Inhibition of affinity purified anti-HNE-HSA IgG by native chromatin, ROS-chromatin and NOchromatin was $44.2 \%, 67.8 \%$, and $66.8 \%$, respectively at $20 \mu \mathrm{g} / \mathrm{ml}$ of inhibitor concentration (Fig. 4c). $8.8 \mu \mathrm{g} / \mathrm{ml}$ of ROS-chromatin was required for $50 \%$ inhibition, whereas $8.2 \mu \mathrm{g} / \mathrm{ml}$ of NO-chromatin was required for $50 \%$ inhibition of anti-HNE-HSA IgG. Competition ELISA with anti-HSA IgG showed a maximum inhibition of $89.3 \%$ with the immunogen as inhibitor and $12.9 \mu \mathrm{g} / \mathrm{ml}$ of immunogen was required for $50 \%$ inhibition in antibody binding. The anti-HSA IgG didn't recognized chromatin and its oxidized forms (Fig. 4d).

\subsection{Detection of SLE autoantibodies directed to HNE-modified epitope $(s)$}

To probe the possible role of the lipid oxidative-by product $\mathrm{HNE}$ and its associated autoimmunity in the 
(a)

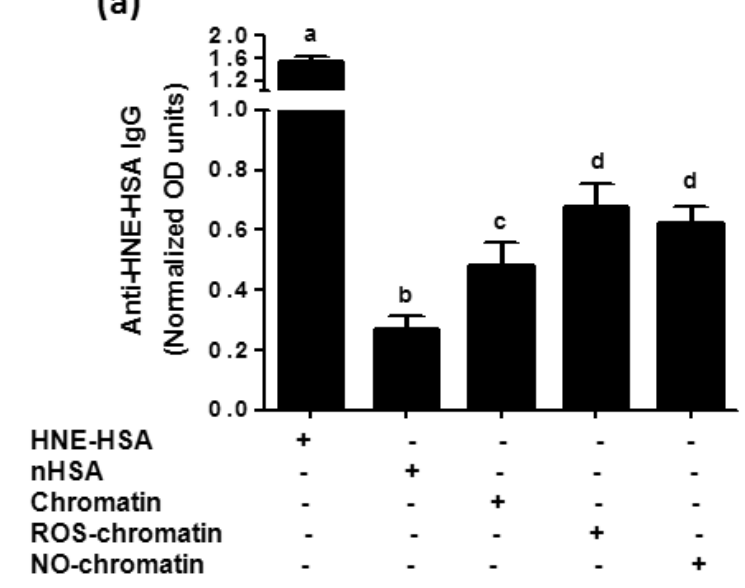

(b)

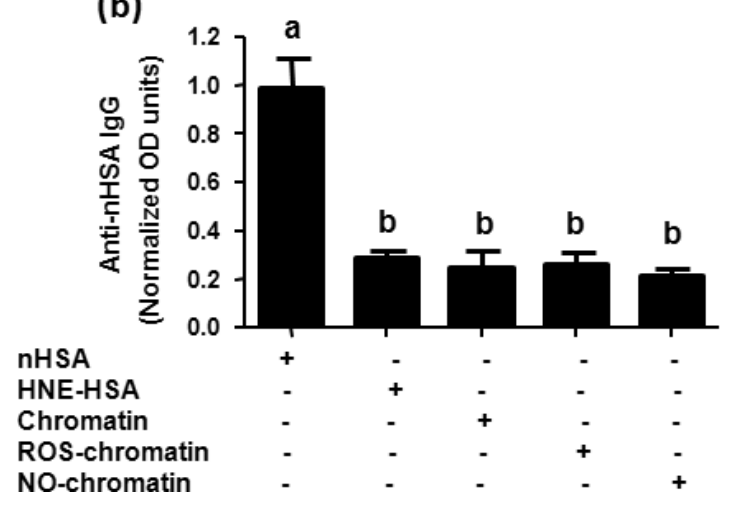

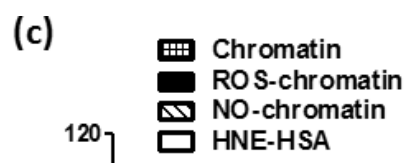
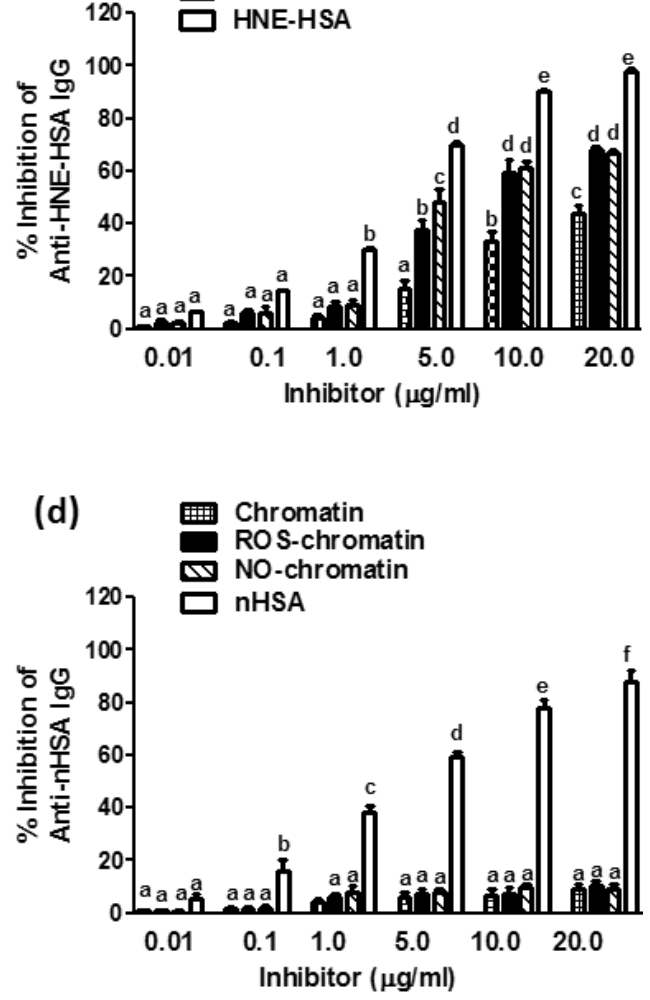

Fig. 4. Recognition of chromatin and its oxidized forms by anti-HNE-HSA IgG. Binding characteristics of affinity purified anti-HNE-HSA $\operatorname{IgG}(\mathrm{a}, \mathrm{c})$ and anti-nHSA IgG $(\mathrm{b}, \mathrm{d})$ to native chromatin (chromatin), reactive oxygen species-modified chromatin (ROS-chromatin), nitric oxide-modified chromatin (NO-chromatin) determined direct binding (a,b) and competitive inhibition (c,d) ELISAs. HNE-HSA and nHSA were used as positive controls with their respective immunogens. Each histogram represents a mean \pm SEM of three independent assays. Data without a common letter differ, $p<0.05$.

pathogenesis of SLE, 74 sera of anti-DNA autoantibodies high titre were selected for the binding to native and HNE-modified protein. Direct binding ELISA showed majority of SLE sera (41/74) showed strong binding to HNE-HSA over native HSA (nHSA) at 1:100 serum dilution $(p<0.05)$ (Fig. 5a). The average absorbance at $410 \mathrm{~nm}( \pm \mathrm{SD})$ of 41 SLE sera binding to HNE-HSA and native HSA was $0.66 \pm 0.23$ and $0.31 \pm 0.01$, respectively. Whereas, the absorbance at $410 \mathrm{~nm}( \pm \mathrm{SD})$ of 35 normal human (NH) sera binding to HNE-HSA and nHSA was $0.18 \pm 0.21$ and $0.19 \pm 0.12$. SLE autoantibodies directed to HNE-HSA was further evaluated by competitive inhibition ELISA. The average percent inhibition ( \pm SD) in the binding of 41 SLE sera to HNE-HSA and nHSA was $47.1 \pm 9.5$ and 14.8 \pm 7.9 , respectively. The data reveals striking differences in the recognition of HNE-HSA and nHSA by SLE autoantibodies $(p<0.001)$. We have also con- ducted similar experiments with NH sera under identical experimental conditions, NH sera showed negligible binding with either of the antigen (Table 1). Native DNA was used as an immunochemical marker for SLE. The average absorbance at $410 \mathrm{~nm}$ ( \pm SD) of 41 SLE sera binding to native DNA was $0.71 \pm 0.25$. Whereas, the absorbance at $410 \mathrm{~nm}( \pm \mathrm{SD})$ of 35 normal human $(\mathrm{NH})$ sera binding to DNA was $0.16 \pm$ 0.15 . Competition assays with DNA reiterate the direct binding ELISA results that SLE autoantibodies showed high degree of specificity towards native DNA (data summarized in Table 1). IgG was purified from 15 most active SLE sera by affinity chromatography using Protein A-Sepharose CL-4B column. The interaction of HNE-modified HSA with affinity purified SLE IgG was as certained by direct binding ELISA. Figure 5b shows the binding of affinity purified SLE IgG to HNEHSA. The average absorbance at $410 \mathrm{~nm}( \pm$ SD) in 


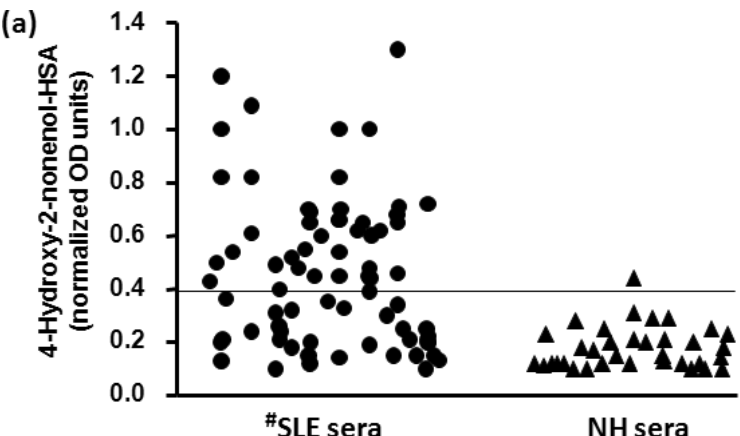

(b)

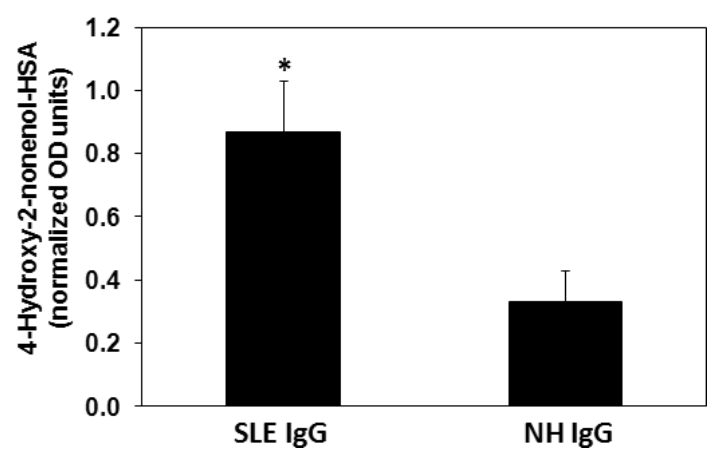

Fig. 5. Binding of SLE autoantibodies to HNE-modified HSA. (a) Direct binding ELISA of circulating antibodies of SLE patients (O) and normal human subjects (NHS;) binding to HNE-modified epitopes. Seventy four SLE patients and thirty five NH sera (1:100 diluted) were analyzed for the binding to HNE-HSA. Values above 0.4 were considered positive (above the line). (b) Direct binding ELISA of affinity purified SLE IgG and normal human (NH) IgG binding to HNE-modified HSA. IgGs were purified from fifteen most active SLE patients and thirteen normal health subjects using protein-A Sepharose CL-4B affinity column. ELISA plates were coated with HNE-HSA $(10 \mu \mathrm{g} / \mathrm{ml}) .{ }^{\#} p<0.01 \mathrm{Vs} \mathrm{NH}$ sera; ${ }^{*} p<0.001 \mathrm{Vs} \mathrm{NH}$ IgG.

the binding of 15 SLE IgG to HNE-HSA was $0.87 \pm$ 4.5. Similar experiments were done with affinity purified normal human $(\mathrm{NH}) \mathrm{IgG}$ used as a control. The average absorbance at $410 \mathrm{~nm}( \pm \mathrm{SD})$ in the binding of $13 \mathrm{NH} \mathrm{IgG}$ to HNE-HSA was $0.43 \pm 2.3$ (Fig. 5b). Native HSA under identical experimental conditions did not showed negligible binding with either SLE IgG or $\mathrm{NH} \mathrm{IgG} \mathrm{and} \mathrm{was} \mathrm{used} \mathrm{as} \mathrm{a} \mathrm{negative} \mathrm{control} \mathrm{(data}$ not shown). The data reveal striking differences in the recognition of native and HNE-modified HSA by SLE antibodies $(p<0.01)$.

The interaction of HNE-modified epitope (s) with SLE autoantibodies was also evaluated by Western immunoblot analysis. Figure 6 shows the binding of most active SLE or NH antibodies to HNE-HSA and nHSA. The data showed striking difference in the recognition of HNE-modified HSA by SLE serum autoantibodies as compared with $\mathrm{NH}$ antibodies present in the serum samples (Fig. 6a). Whereas neither SLE nor NH serum antibodies showed reactivity with nHSA (Fig. 6b). Experimentally induced antibodies against HNE-HSA or nHSA used as positive controls. Interaction of HNE-HSA with purified SLE IgG was also determined by Western immunoblot analysis under identical experimental conditions as with SLE sera. Results obtained were same as we obtained with serum samples (Figs 6c\&d). The data showed that 4-hydroxyl2-noneol modified epitope(s) were well recognized by SLE autoantibodies (Fig. 6).

\subsection{Recognition of chromatin, ROS-chromatin and NO-chromatin by SLE autoantibodies}

The binding specificity of Protein-A sepharose purified SLE IgGs from 22 selected sera of SLE patients was evaluated by competitive inhibition ELISA using native chromatin, ROS-chromatin and NO-chromatin as inhibitors (Fig. 7a). Whereas, HNE-HSA was used as positive control and nHSA was used a negative controls. Results showed higher reactivity of autoantibodies in patient's sera towards HNE-HSA, n-chromatin, ROSchromatin and NO-chromatin, whereas nHSA didn't recognized by SLE IgG. The average percent inhibition $( \pm$ SEM) in the binding of 22 SLE sera to HNEHSA by HNE-HSA, chromatin, ROS-chromatin, NOchromatin and nHSA was $61.1 \pm 6.5,39.2 \pm 4.7$, $50.5 \pm 4.7,54.5 \pm 2.8$ and $13.3 \pm 4.7$, respectively. Native DNA (nDNA) was used as immunochemical marker for SLE and was strongly recognized by affinity purified SLE IgGs. Furthermore, we have also tested affinity purified $\mathrm{NH}$ antibodies for the recognition of the same chromatin and its oxidative forms under identical experimental conditions as with SLE antibodies. Results revealed that $\mathrm{NH}$ IgGs showed insignificant binding to all the tested inhibitors ( $p>0.05$; Fig. 7b). Data pointed out a significant difference in the recognition of HNE-HSA, chromatin and its oxidative forms by SLE antibodies, when compared with the antibodies from normal human controls ( $p<0.0001)$ (Fig. 7).

\subsection{Recognition of HNE-modified epitope $(s)$ by anti-chromatin, anti-ROS-chromatin or anti-NO-chromatin SLE antibodies}

Direct binding ELISA of immunoprecipitation purified anti-chromatin, anti-ROS-chromatin and anti-NOchromatin SLE IgGs showed strong binding with HNEmodified HSA as compared with nHSA $(p<0.001)$ (Fig. 8). The average absorbance at $410 \mathrm{~nm}( \pm$ SEM $)$ of 
Table 1

Immunological details of study subjects

\begin{tabular}{llcc}
\hline Parameters & & SLE-sera & NH-sera \\
\hline Age & & $45.2 \pm 17.6(n=41)$ & $42.1 \pm 18.2(n=35)$ \\
Sex & & $39 \mathrm{~F} / 2 \mathrm{M}$ & $32 \mathrm{~F} / 3 \mathrm{M}$ \\
Detection of anti-HNE-HSA antibodies & A $_{410}$ (HNE-HSA) & $0.66 \pm 0.23^{\mathrm{a}}$ & $0.18 \pm 0.0^{\mathrm{b}}$ \\
& MPI (HNE-HSA) & $47.1 \pm 9.5^{\mathrm{d}}$ & $13.3 \pm 4.7^{\mathrm{e}}$ \\
Detection of anti-nHSA antibodies & A $_{410}$ (nHSA) & $0.31 \pm 0.10^{\mathrm{c}}$ & $0.19 \pm 0.12^{\mathrm{b}}$ \\
& MPI (nHSA) & $14.8 \pm 7.9^{\mathrm{e}}$ & $12.9 \pm 8.2^{\mathrm{e}}$ \\
& A & $0.71 \pm 0.25^{\mathrm{a}}$ & $0.16 \pm 0.15^{\mathrm{b}}$ \\
& MPI (dsDNA) & $56.7 \pm 10.3^{\mathrm{f}}$ & $12.3 \pm 5.7^{\mathrm{e}}$ \\
\hline
\end{tabular}

ELISA plates were individually coated with native HSA, HNE-HSA or native DNA. Unbound protein or DNA were washed with tris buffer saline containing tween-20 (TBS-T) and unoccupied sites were blocked with $2 \%$ fat free milk solution. Test serum in direct binding assays or antigen-serum mixture in inhibition immunoassays were then coated and bound antibodies were assayed using anti-human alkaline phosphatase conjugate (catlog \# A3187; Sigma-Aldrich) and p-nitrophenyl phosphate (catalog \# 71768; Sigma-Aldrich) as described in methods section. Percent inhibition in competitive inhibition assays was calculated using the formula: Percent inhibition $=1-\left[\left(\mathrm{A}_{\text {inhibited }} / \mathrm{A}_{\text {uninhibited }}\right)\right] \times 100$. Abbreviations: SLE-sera: sera from systemic lupus erythematosus patients; $\mathrm{NH}$-sera: sera from normal human subjects; $\mathrm{n}$ : number of samples tested; F: females; M: males; nHSA: native HSA; $\mathrm{A}_{410}$ : absorbance at $410 \mathrm{~nm}$ calculated by direct binding ELISA; MPI: maximum percent inhibition at $20 \mu \mathrm{g} / \mathrm{ml}$ of inhibitor concentration calculated by competitive inhibition ELISA; dsDNA: native calf thymus double stranded DNA used as a positive control for SLE patients. Data represents as mean $\pm \mathrm{SD}$. Data without a common letter differ, $p<0.05$.
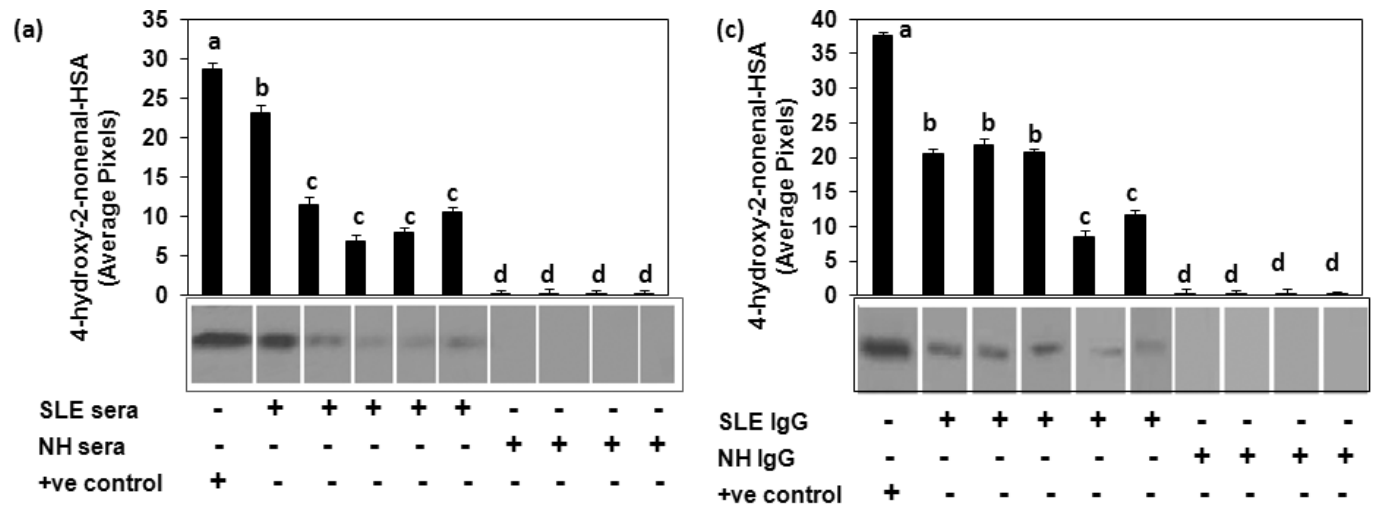

(b)

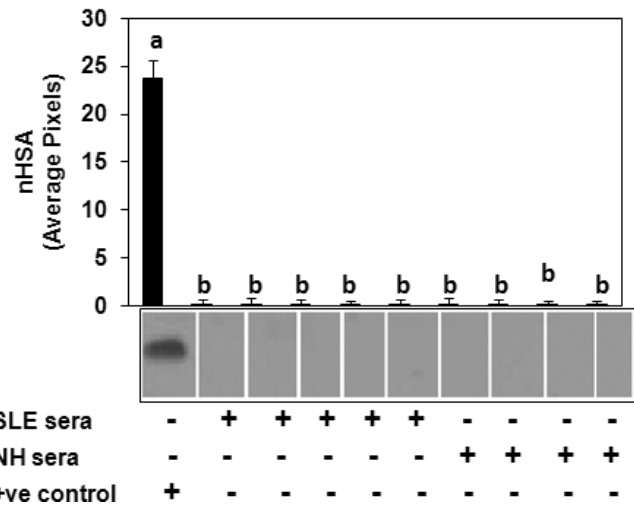

(d)

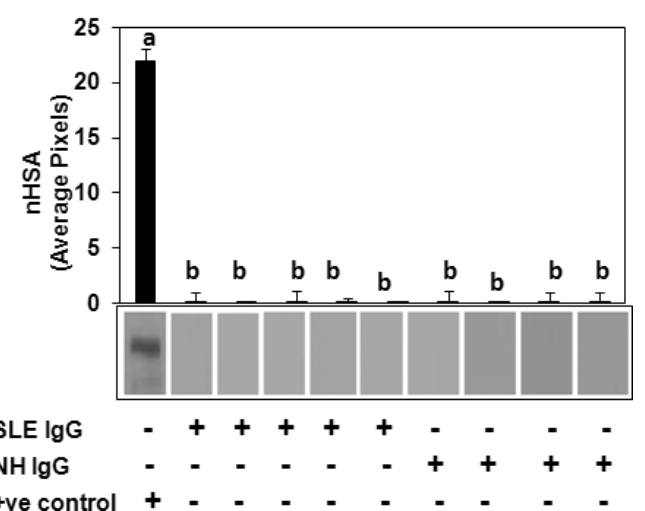

Fig. 6. Immunoblot analysis of SLE autoantibodies binding to HNE-modified HSA. Western immunoblot of antibodies from SLE and normal human serum samples binding to HNE-modified protein (a) and unmodified protein (b). Western immunoblot of affinity purified IgG from SLE and normal human subjects binding to HNE-HSA (c) and HSA (d). HNE-HSA or nHSA (40 $\mu \mathrm{g}$ ) was resolved on 4\%-20\% gradient SDS-PAGE and transfer to PVDF immobilon-P membranes. The membrane was then excised into strips and each membrane strip was blocked with non-fat dry milk powder in Tris buffered saline and $0.1 \%$ Tween-20 (TBS-T). Each strip was probed with serum samples (1:100 diluted) or affinity purified IgG samples (1:500 diluted). Experimentally induced anti-HNE-HSA antibodies or anti-nHSA antibodies were used as positive controls. Band images were digitally captured and the band intensities were obtained using UN-San-It software (Silk Scientific Corporation, Orem, UT, USA) and are expressed in average pixels/band. Average pixel values presented as Mean $\pm \mathrm{SD}$; data without a common letter differ, $P<0.05$. 
(a)
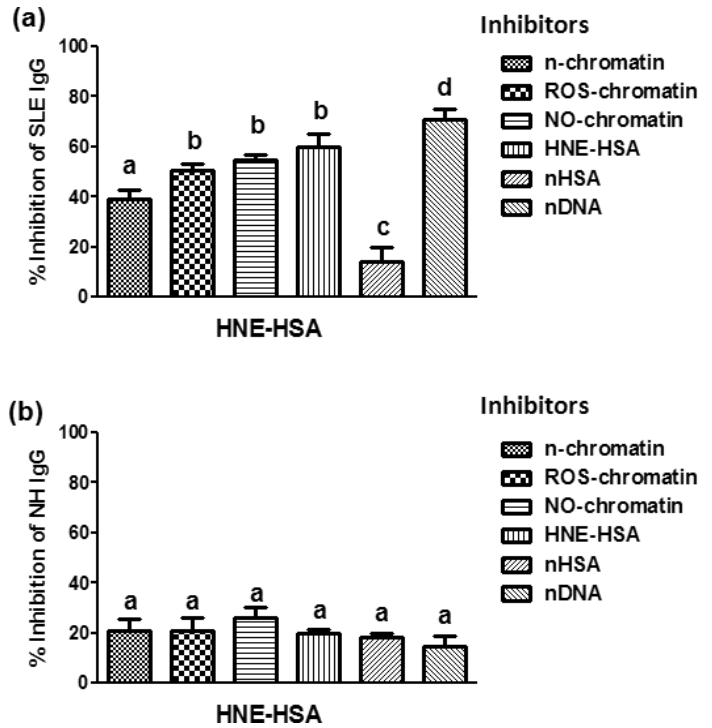

Fig. 7. Competitive inhibition of SLE IgG. Inhibition of affinity purified SLE IgG (a) and normal human IgG (b) binding to HNE-modified protein. Inhibitors used were native chromatin (n-chromatin), ROS-modified chromatin (ROS-chromatin), nitric oxide-modified chromatin (NO-chromatin), HNE-modified protein (HNE-HSA) and native protein (nHSA). Native calf thymus dsDNA used as a positive control for SLE patients. Inhibitors concentration used in the competitive binding assays was $20 \mu \mathrm{g} / \mathrm{ml}$. Microtitre plates were coated with HNE-HSA $(10 \mu \mathrm{g} / \mathrm{ml})$. The number of SLE samples used was 22. Each histogram represents a mean \pm SEM of four independent assays. Data without a common letter differ, $p<0.05$.

three independent assays with anti-chromatin SLE IgG binding to HNE-HSA and native HSA was $0.35 \pm 0.06$ and $0.09 \pm 0.04$, respectively. Whereas, the average absorbance at $410 \mathrm{~nm}( \pm$ SEM) of three independent assays with anti-ROS-chromatin SLE IgG binding to HNE-HSA and native HSA was $0.48 \pm 0.03$ and 0.09 \pm 0.03 , respectively and with anti-NO-chromatin SLE $\mathrm{IgG}$ the average absorbance was $0.54 \pm 0.05$ and 0.10 \pm 0.05 , respectively (Fig. 8).

\subsection{Identification of lipid peroxidative damaged in albumin purified from SLE patients}

To investigate the HNE modifications in HSA of SLE patients, HSA was isolated from 15 most active SLE patients (SLE-HSA) and also from 13 normal healthy subjects (NH-HSA). The purified HSA was found to elute in a single symmetrical peak on Sephacryl S-200 HR column (Fig. 9). SDS-PAGE of purified HSA showed a single homogenous band (Fig. 9 inset). HNE generated epitope(s) on SLE-HSA were identified by Western immunoblot analysis using commercially HNE-specific monoclonal antibodies. Our results showed that SLE-

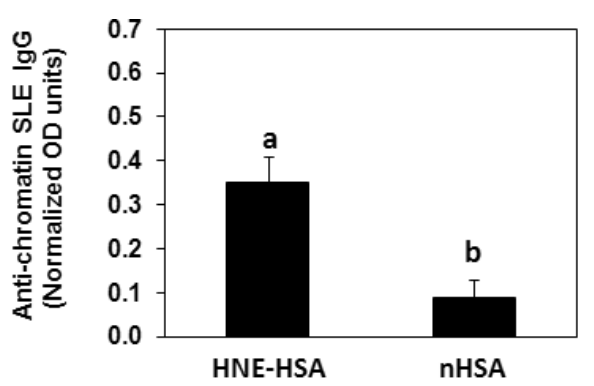

(a)

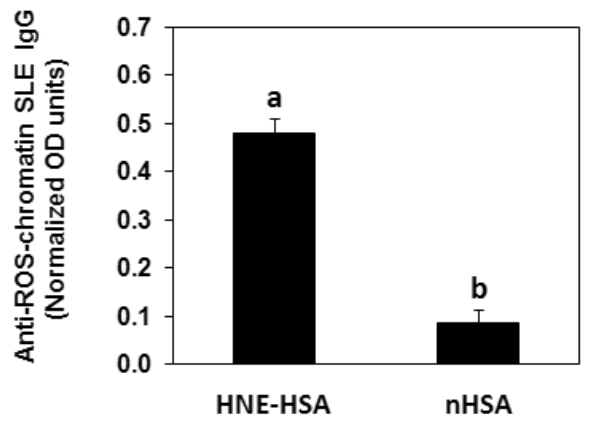

(b)

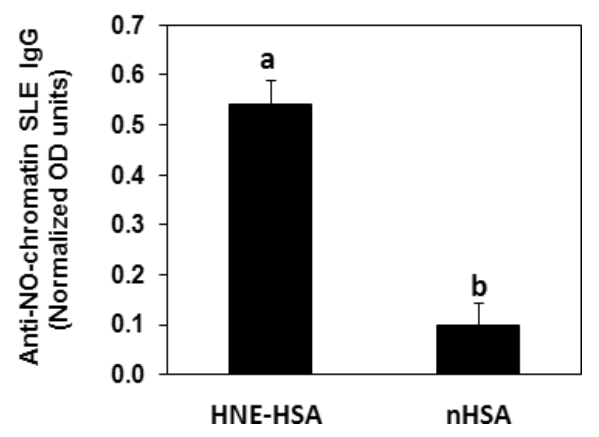

(c)

Fig. 8. Immunoprecipitation of SLE autoantibodies with chromatin or its oxidized forms, followed by direct binding ELISA with native and HNE-modified HSA. Immunoprecipited SLE anti-chromatin IgG, anti-ROS-chromatin IgG and anti-NO-chromatin IgG were eluted from Protein- $\mathrm{G}$ beads by changing the $\mathrm{pH}$ and were used in ELISA with native and HNE-HSA as antigens. Data shown are cumulative of three experiments and values are presented as Mean \pm SEM; data without a common letter differ, $p<0.05$.

HSA was well recognized by anti-HNE-specific antibodies, whereas these antibodies were failed to recognize NH-HSA (Fig. 10a). We have also demonstrated, HNE-induced modifications in SLE-HSA by carbonyl estimation. The average carbonyl contents $( \pm$ SD) of five independent assays of SLE-HSA and NH-HSA were $2.3 \pm 0.15$ and $1.69 \pm 0.11 \mathrm{nmol} / \mathrm{mg}$ protein, respectively (Fig. 10b), a p value of 0.01 indicates significant difference in the carbonyl contents of SLE-HSA 


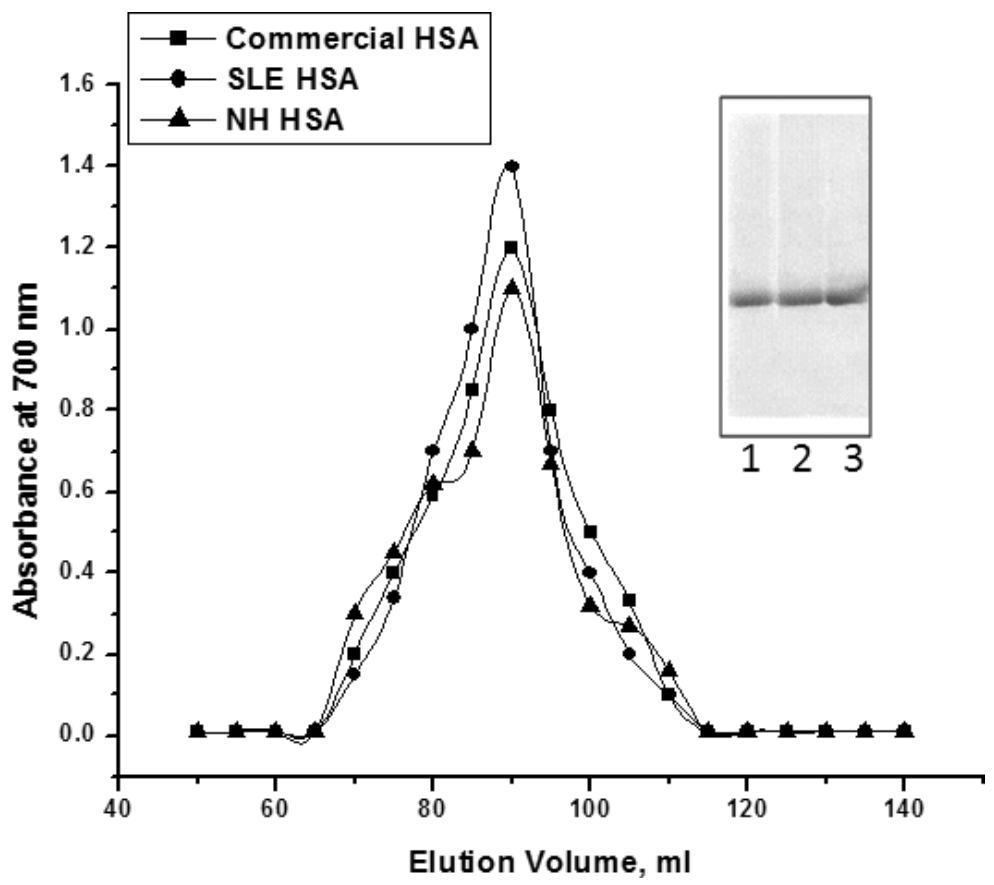

Fig. 9. Purification of HSA from SLE patients. Elution profiles of purified HSA from SLE patients $(\boldsymbol{\Delta})$ and normal humans subjects $(\boldsymbol{\square})$ on Sephacryl S-200 HR column. Commercial HSA (O) was also eluted from the same column and was used as a marker. Protein in each fraction was monitored by the method of Lowry et al. (1951). Inset: Native PAGE of purified HSAs, and commercial HSA on $7.5 \%$ gel. Lane 1 contains eluted commercial HSA, lane 2 and 3 contain purified HSA from normal human and SLE patient's, respectively.

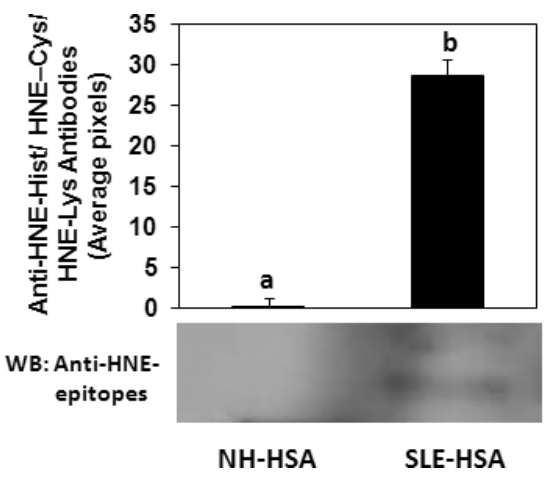

(a)

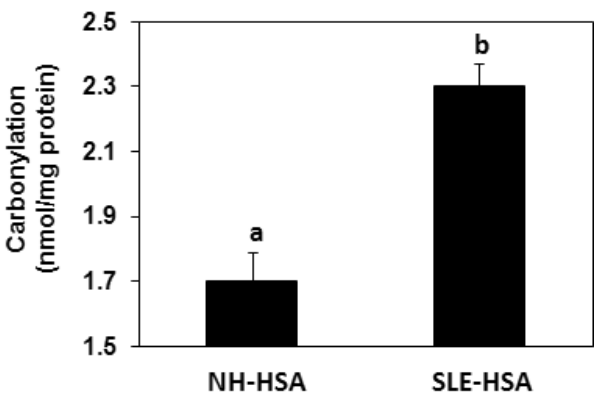

(b)

Fig. 10. Characterization of HSA from SLE patients. (a) Immunoblot analysis of HSA from SLE patients (SLE-HSA) and normal human subjects (NH-HSA). SLE-HSA and NH-HSA were probed with commercial anti-HNE-monoclonal antibodies. Band images were digitally captured and the band intensities (pixels/band) were obtained using the Un-Scan-It software. Average pixel values presented as Mean \pm SD; data without a common letter differ, $p<0.05$. (b) Carbonyl contents in SLE-HSA and NH-HSA. The protein concentration in both HSA samples was $15 \mu \mathrm{M}$. Each histogram represents the mean \pm SEM of five independent assays. Data without a common letter differ, $p<0.001$.

and NH-HSA. In addition, HNE generated epitopes on SLE-HSA were further screened by experimentally induced rabbit anti-HNE-HSA IgG. The average absorbance at $410 \mathrm{~nm}( \pm \mathrm{SEM})$ of three independent assays of anti-HNE-HSA IgG binding to SLE-HSA and NH-HSA was $0.45 \pm 0.06$ and $0.097 \pm 0.05$, respec- tively (Fig. 11a). Whereas, the absorbance at $410 \mathrm{~nm}$ $( \pm$ SEM) of three assays with induced anti-nHSA IgG binding to SLE-HSA and NH-HSA was $0.18 \pm 0.03$ and $0.16 \pm 0.02$, respectively (Fig. 11b). Data clearly pointed out that SLE-HSA was well recognized by anti-HNE-HSA IgG. No appreciable binding was ob- 


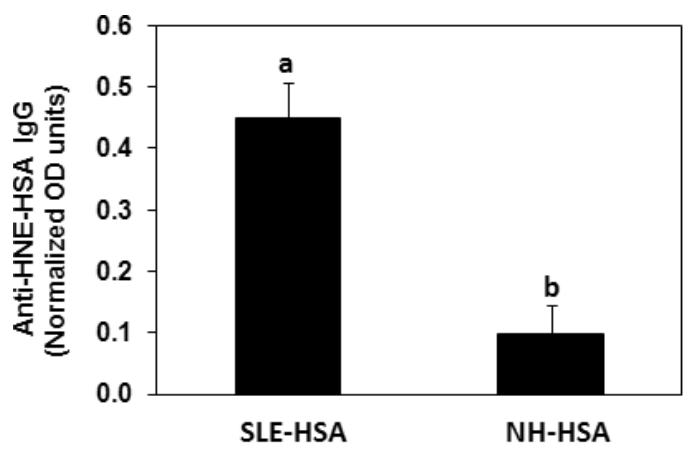

(a)

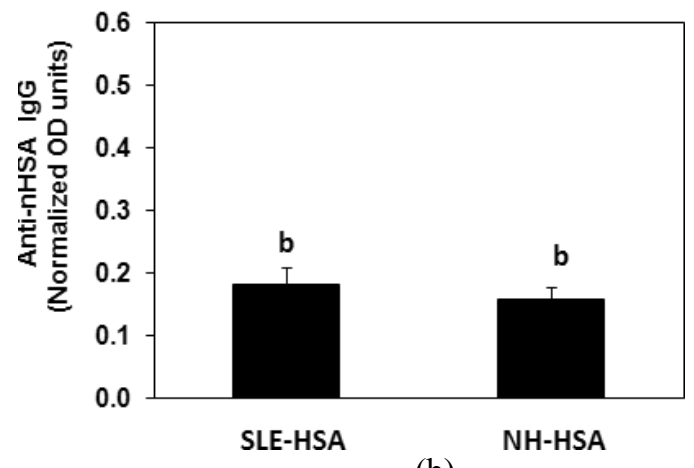

(b)

Fig. 11. Binding characteristics of anti-HNE-HSA IgG binding to SLE-HSA. Direct binding ELISA of experimentally induced rabbit anti-HNE-HSA IgG and anti-nHSA IgG to purified HSA samples from SLE patients (SLE-HSA) and normal human subjects (NH-HSA). ELISA plates were coated with SLE-HSA or NH-HSA $(10 \mu \mathrm{g} / \mathrm{ml})$. Each histogram represents the mean \pm SEM of four independent assays. Data without a common letter differ, $p<0.001$.

served between anti-nHSA IgG and SLE-HSA. Whereas, NH-HSA under identical experimental conditions didn't recognized by neither anti-HNE-HSA IgG or nor by anti-nHSA IgG (Fig. 11).

\section{Discussion}

In the present study, commercially available HSA was modified with HNE in-vitro, HNE generated neoepitope(s) were characterized by commercially available HNE-specific antibodies (Shizuoka, Japan) and by carbonyl formation. Modified HSA was found to be a potent antigenic stimulus inducing high titre antibodies in rabbits, whereas with nHSA, low titre antibodies were obtained. The antigenic specificity of affinity purified anti-HNE-HSA IgG and anti-nHSA IgG reiterated that induced antibodies were immunogen specific. The substantially enhanced immunogenicity of
HNE-HSA in comparison to nHSA could possibly be due to the HNE-generated neo-epitopes. Anti-dsDNA antibodies are often considered to be a hallmark of SLE [32]. However, evidence has accumulated in recent years that anti-chromatin autoantibodies are correlated even better than anti-dsDNA in SLE [33,34]. Chromatin is an antigen for $\mathrm{T}$ and $\mathrm{B}$ cells from patients with SLE [35]. Additionally, anti-chromatin antibodies are a ubiquitous feature of murine SLE [35] and are necessary but not sufficient for the development of glomerulo nephritis in one strain of mouse [36]. It was found that anti-chromatin always preceded the appearance of anti-dsDNA antibodies in two strains of mice, and the suggestion was made that anti-dsDNA antibodies were a subset of anti-chromatin antibodies [37]. For these reasons, we have tested the specificity of experimentally induced antibodies against HNE-modified epitope(s) towards chromatin and its oxidized forms. Our results showed that affinity purified anti-HNEHSA antibodies showed cross reactions with chromatin, ROS-chromatin and NO-chromatin. Whereas, induced antibodies against nHSA showed negligible binding to these nucleic acid antigens. Therefore, it was thought worthwhile to investigate the binding characteristics of natural occurring SLE autoantibodies to HNE-damaged HSA, so that the possible involvement of HNE-modified epitopes could be ascertained. Sera of 74 SLE patients having high anti-DNA antibodies titre and 35 normal human $(\mathrm{NH})$ subjects were collected for the present study. Of these, 55.4\% SLE sera showed preferentially high binding to HNE-modified HSA as compared to its native analogue as determined by direct binding ELISA. No appreciable binding was observed with the normal human subjects. These results were further confirmed with Protein-A purified IgGs from the same SLE patients. Competitive inhibition ELISA reiterated the direct binding results, that the HNE-modified HSA was an effective inhibitor, showing substantial difference in the recognition of SLE IgG over normal human IgG. Previously it was reported that the differential immobilization of HNE-modified proteins and unmodified proteins to ELISA plates (since binding to plastic is charge/conformation dependent) [22]. With the modification of histidine and lysines by HNE, the protein tends to lose positive charges due to these amino acids, and thereby become more negatively charged. This enables the modified proteins to bind to ELISA plates better than the unmodified proteins, thereby skewing the results obtained and it was also reported that the conformation of the protein also changes following modification, which may also affect the binding of the protein 
to the solid surface [22]. To rule out this possibility of our ELISA results with HNE-modified HSA, we also performed some of ELISA experiments by modifying a solid phase protein as described previously [22]. Results obtained with this methods were little bit difference in the binding of antibodies with pre- and postimmobilization of the HNE-antigens but the overall pattern for the recognition of antibodies to HNE-modified antigen was same. Furthermore, this possibility of differential immobilization of HNE-modified antigen was further ruled out by Western immunoblot analysis. Innumoblot data further substantiates the enhanced binding of HNE-modified epitopes towards SLE autoantibodies as compared with antibodies present in normal human subjects. In addition, we have also tested the same SLE sera or SLE IgG for the detection of SLE autoantibodies specificity towards chromatin and its oxidized forms. All the sera or IgGs tested showed preferentially high binding to ROS-modified or NO-modified chromatin as compared to unmodified chromatin. Thus by employing these immunological techniques, the data clearly demonstrates a substantial increase in the recognition of HNE-modified HSA, ROS-modified chromatin and NO-modified chromatin by circulating SLE autoantibodies.

Furthermore, we have also investigated the HNEinduced alterations of HSA in SLE patients, HSA was isolated from 15 most active SLE patients (SLEHSA) and also from 13 normal human subjects (NHHSA) and their carbonyl contents or immunoreactivity towards HNE-specific antibodies were compared. Our data showed that SLE-HSA contained significantly high carbonyl contents as compared with NH-HSA $(p<0.01)$. In this context, it is important to point out that the oxidation of a protein typically results in an increase in carbonyl contents. This increase is due to the oxidation of many amino acid residues including Lys, His, Cys [38,39]. Now, it is also well reported that HSA adducted with HNE in human serum is considered to be a potential biomarker of carbonylation damage in human $[29,40]$ and many investigators are now trying to make their strategies that will inhibits the formation of advanced lipoxidation end-products based on carbonylsequestering agents and it seems to be the most promising pharmacological tool $[41,42]$. In view of these, we have estimated HNE-induced modifications in term of carboylation. HNE generated eipitope(s) were further analyzed by detection of HNE-adducted His, Cys, or Lys by Western immunoblot analysis using commercially available anti-HNE-specific monoclonal antibodies. These HNE-specific antibodies showed strong binding with SLE-HSA, but not with NH-HSA. This clearly indicated that SLE-HSA was HNE modified. In addition, we have also confirmed HNE-induced modifications in SLE-HSA by experimentally induced rabbit anti-HNE-HSA IgG. Anti-HNE-HSA IgG showed binding with SLE-HSA, but not with NH-HSA. Whereas, experimentally induced IgG against nHSA did not showed binding either with SLE-HSA or with NHHSA. All these data confirmed that SLE-HSA was HNE modified. Furthermore, we have also demonstrated that immunoprecipated anti-chromatin IgG, antiROS-chromatin IgG, or anti-NO-chromatin IgG from SLE patients showed immunocross-reactions with invitro generated HNE-HSA. Therefore, all these results demonstrated that HSA and chromatin in SLE patients were oxidatively modified, which might play an active part in the progression of disease. The present study further propose that, in addition to HSA in serum concentration and chromatin in nucleus of affected cells, the quality of HSA or chromatin molecules may be not only a crucial factor affecting their normal functions, but also a risk factor as a pro-oxidant in lupus patients. In conclusion, our data demonstrated that exposure of HNE caused oxidative damaged to proteins and presents unique epitopes for the generation of autoantibodies specific to chromatin and its oxidized forms. HSA modified with HNE and chromatin modified with reactive oxygen/nitrogen species may be important factors for the induction of circulating SLE autoantibodies. These findings contribute to a paradigm of lipid peroxidation and ROS/RNS products causing at least some autoimmune diseases.

\section{Conflicts of interest}

The authors declare that they have no conflicts of interest.

\section{Authors' contributions}

HAA, AAR, AAA carried out the experimental work, collection, interpretation and manuscript drafting. ZR conceived of the study, its design, experimentation, coordination, data interpretation and manuscript drafting. All authors have read and approved the final manuscript.

\section{Acknowledgements}

This work was supported in part by Research Deanship Grant \# 952 and funds from College of Medicine, 
Qassim University. ZR also thanks Professor A. Alghasham (Dean, College of Medicine) for providing research facilities. Thanks are also due to Dr. R. Mehala, School of Medicine, University of South Carolina, USA. for performing some of our Western Immunoblotting experiments.

\section{References}

[1] K. Uchida, 4-Hydroxy-2-nonenal: a product and mediator of oxidative stress. Prog Lipid Res 42(2003), 318-343.

[2] K. Toyoda, R. Nagae, M. Akagawa, K. Ishino, T. Shibata, S. Ito, N. Shibata, T. Yamamoto, M. Kobayashi, Y. Takasaki, T. Matsuda, K. Uchida, Protein-bound 4-hydroxy-2-nonenal: an endogenous triggering antigen of anti-DNA response. $J$ Biol Chem 282(2007), 25769-25778.

[3] M. Akagawa, S. Ito, K. Toyoda, Y. Ishii, E. Tatsuda, T. Shibata, S. Yamaguchi, Y. Kawai, K. Ishino, Y. Kishi, T. Adachi, T. Tsubata, Y. Takasaki, N. Hattori, T. Matsuda, K. Uchida, Bispecific abs against modified protein and DNA with oxidized lipids. Proc Natl Acad Sci USA 103(2006), 6160-6165.

[4] B.T. Kurien, R.H. Scofield, Autoimmunity and oxidatively modified autoantigens. Autoimmun Rev 7(2008), 567-573.

[5] H.F. Poon, R.A. Vaishnav, T.V. Gelchell, M.L. Getchell, D.A. Butterfield, Quantitative proteomics analysis of differential protein expression and oxidative modification of specific proteins in the brains of old mice. Neurobiol Aging 27(2006), 1010-1019.

[6] Z. Rasheed, R. Ali, Reactive oxygen species damaged human serum albumin in patients with type 1 diabetes mellitus: biochemical and immunological studies. Life Sci 79(2006), 2320-2328.

[7] Z. Rasheed, R. Ahmad, N. Rasheed, R. Ali, Enhanced recognition of reactive oxygen species damaged human serum albumin by circulating systemic lupus erythematosus autoantibodies. Autoimmunity 40(2007), 512-520.

[8] M. Wong, A. La Cava, Lupus, the current therapeutic approaches. Drugs Today (Barc) 47(2011), 289-302.

[9] R. Gualtierotti, M. Biggioggero, A.E. Penatti, P.L. Meroni, Updating on the pathogenesis of systemic lupus erythematosus. Autoimmun Rev 10(2010), 3-7.

[10] P.V. Lehmann, E.E. Sercarz, T. Forsthuker, C.M. Doyan, G. Gammon, Determinant spreading and the dynamics of the autoimmune T-cell repertoire. Immunol Today 14(1993), 203208.

[11] J.W. Dieker, J. van der Vlag, J.H. Berden, Triggers for antichromatin autoantibody production in SLE. Lupus 11 (2002), 856-864.

[12] J.A. Simon, J. Cabiedes, E. Ortiz, J. Alcocer-Varela, J. Sánchez-Guerrero, Anti-nucleosome antibodies in patients with systemic lupus erythematosus of recent onset. Potential utility as a diagnostic tool and disease activity marker. Rheumatology (Oxford) 43 (2004), 220-224.

[13] B.T. Kurien, A. Porter, Y. Dorri, S. Iqbal, A. D’Souza, A. Singh, S. Asfa, M. Cartellieri, K. Mathias, H. Matsumoto, M. Bachmann, K. Hensley, R.H. Scofield, Degree of modification of Ro60 by the lipid peroxidation by-product 4-hydroxy-2nonenal may differentially induce Sjögren syndrome or systemic lupus erythematosus in BALB/c mice. Free Radic Biol Med 50 (2011), 1222-1233
[14] Y. Liu, G. Xu , L.M. Sayre. Carnosine inhibits (E)-4-hydroxy2-nonenal-induced protein cross-linking: structural characterization of carnosine-HNE adducts. Chem Res Toxicol 16 (2003), 1589-1597.

[15] E. Harlow, D. Lane D. 1988. Antibodies: A laboratorymanual. Cold Spring Harbor Laboratory Press, Cold Spring Harbor, New York.

[16] J. Bonner, G.R. Chalkley, M. Dahmus, D. Fambrough, F. Fujimura, R.C. Huang, Isolation and characterization of chromosomal nucleoproteins. Methods Enzymol XIIB(1968), 3-8.

[17] F. Mansoor, A. Ali, R. Ali, Binding of circulating SLE autoantibodies to oxygen free radical damaged chromatin. Autoimmunity 38 (2005), 431-438.

[18] H. Ohshima, M. Friesen, I. Brouet, H. Bartsch, Nitrotyrosine as new marker for endogenous nitrosation and nitration of proteins. Food Chem Toxicol 28 (1990), 647-652.

[19] B. Shen, R. G. Jensen, H. J. Bohnert, Mannitol Protects against Oxidation by Hydroxyl Radicals. Plant Physiol 115 (1997), 527-532.

[20] C.G. Millar, C. Thiemermann, Carboxy-PTIO, a scavenger of nitric oxide, selectively inhibits the increase in medullary perfusion and improves renal function in endotoxemia. Shock 18 (2002), 64-68

[21] M.C. Hochberg, For the Diagnostic and Therapeutic Criteria Committee of the American College of Rheumatology. Updating the American College of Rheumatology revised criteria for the classification of systemic lupus erythematosus [letter]. Arthritis Rheum 40 (1997), 1725.

[22] B.T. Kurien, R.H. Scofield. In vitro modification of solid phase multiple antigenic peptides/autoantigens with 4-hydroxy-2nonenal (HNE) provide ideal substrates for detection of antiHNE antibodies and peptide antioxidants. J Immunol Methods 303 (2005), 66-75.

[23] Z. Rasheed, Hydroxyl radical damaged Immunoglobulin G in patients with rheumatoid arthritis: biochemical and immunological studies. Clin Biochem 2 (2008), 1-13.

[24] Z. Rasheed, H.A. Al-Shobaili, A.A. Alzolibani, M. Ismail Khan, M. Tariq Ayub, M.I. Khan, N. Rasheed, Immunological functions of oxidized human immunoglobulin $\mathrm{G}$ in type $1 \sim$ diabetes mellitus: Its potential role in diabetic smokers as a biomarker of elevated oxidative stress. Dis Markers 31 (2011), 47-54.

[25] J.W. Goding, Use of staphylococcal Protein-A as immunological reagent. J Immunol Methods 20 (1978), 241-254.

[26] S. Tayyab, M.A. Qasim. Purification and properties of buffalo serum albumin. Biochem Int 20 (1990), 405-415.

[27] O.H. Lowry, N.J. Rosebrough, A.L. Farr, R.J. Randall. Protein measurement with the Folin phenol reagent. J Biol Chem 193 (1951), 265-275.

[28] B.T. Kurien, R.H. Scofield, Free radical mediated peroxidative damage in systemic lupus erythematosus. Life Sci 73 (2003), $1655-1666$.

[29] G. Aldini, L. Gamberoni, M. Orioli, G. Beretta, L. Regazzoni, R. Maffei Facino, M. Carini, Mass spectrometric characterization of covalent modification of human serum albumin by 4-hydroxy-trans-2-nonenal. J Mass Spectrom 41 (2006), 1149-1161

[30] M.E. Szapacs, J.N. Riggins, L.J. Zimmerman, D.C. Liebler, Covalent adduction of human serum albumin by 4-hydroxy2-nonenal: kinetic analysis of competing alkylation reactions. Biochemistry 45 (2006), 10521-10528.

[31] S. Toyokuni, S. Yamada, M. Kashima, Y. Ihara, Y. Yamada, T. Tanaka, H. Hiai, Y. Seino, K. Uchida, Serum 4-hydroxy-2- 
nonenal-modified albumin is elevated in patients with type 2 diabetes mellitus. Antioxid Redox Signal 2 (2000), 681-685.

[32] B. Diamond, O. Bloom, Y. Al Abed, C. Kowal, P.T. Huerta, B.T. Volpe, Moving towards a cure: blocking pathogenic antibodies in systemic lupus erythematosus. J Intern Med 269 (2011), 36-44.

[33] A. Souza, L.M. da Silva, F.R. Oliveira, A.M. Roselino, P. Louzada-Junior, Anti-nucleosome and anti-chromatin antibodies are present in active systemic lupus erythematosus but not in the cutaneous form of the disease. Lupus 18 (2009), 223-229.

[34] Z. Amoura, J-C. Piette, J-F, Bach, S. Koutouzov, The key role of nucleosomes in lupus. Arthritis Rheum 42 (1999), 833-843.

[35] A. Bruns, S. Bläss, G. Hausdorf, G.R. Burmester, F. Hiepe, Nucleosomes are major T and B cell autoantigens in systemic lupus erythematosus. Arthritis Rheum 43 (2000), 2307-2315.

[36] L. Morel, K.R. Blenman, B.P. Croker, E.K. Wakeland, The major murine systemic lupus erythematosus susceptibility locus, SLE1, is a cluster of functionally related genes. Proc Natl Acad Sci USA 98 (2001), 1787-1792.

[37] R.W. Burlingame, R.L. Rubin, R.S. Balderas, A.N. Theofilopoulos, Genesis and evolution of antichromatin autoantibodies in murine lupus implicates T-dependent immunization with self antigen. J Clin Invest 91 (1993), 1687-1696.

[38] I. Dalle-Donne, A. Scaloni, D. Giustarini, E. Cavarra, G. Tell, G. Lungarella, R. Colombo, R. Rossi, A. Milzani, Proteins as biomarkers of oxidative/nitrosative stress in diseases: the contribution of redox proteomics. Mass Spectrom Rev 24 (2005), 55-99.

[39] I. Dalle-Donne, R. Rossi, D Giustarini, A. Milzani, R, Colombo, Protein carbonyl groups as biomarkers of oxidative stress. Clin Chim Acta 329 (2003), 23-38.

[40] G. Aldini, L. Gamberoni, M. Orioli, L. Regazzoni, G. Beretta, R. M. Facino, M. Carini, Mass Spectrometric Identification of Albumin as a Protein Target of 4-hydroxy-trans-2-nonenal in Human Serum: A Potential Biomarker of Carbonylation Damage? THP-046 (2006), Biomarkers session, $17^{\text {th }}$ IMSC.

[41] G. Aldini, I. Dalle-Donne, R.M. Facino, A. Milzani, M. Carini, Intervention strategies to inhibit protein carbonylation by lipoxidation-derived reactive carbonyls. Med Res Rev 27 (2007), 817-68.

[42] G. Aldini, I. Dalle-Donne, R. Colombo, R Maffei Facino, A. Milzani, M. Carini. Lipoxidation-derived reactive carbonyl species as potential drug targets in preventing protein carbonylation and related cellular dysfunction. ChemMedChem 1 (2006), 1045-58. 


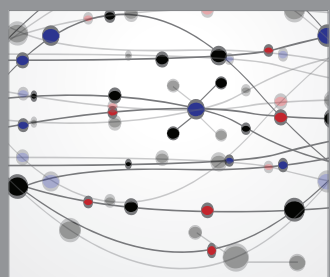

The Scientific World Journal
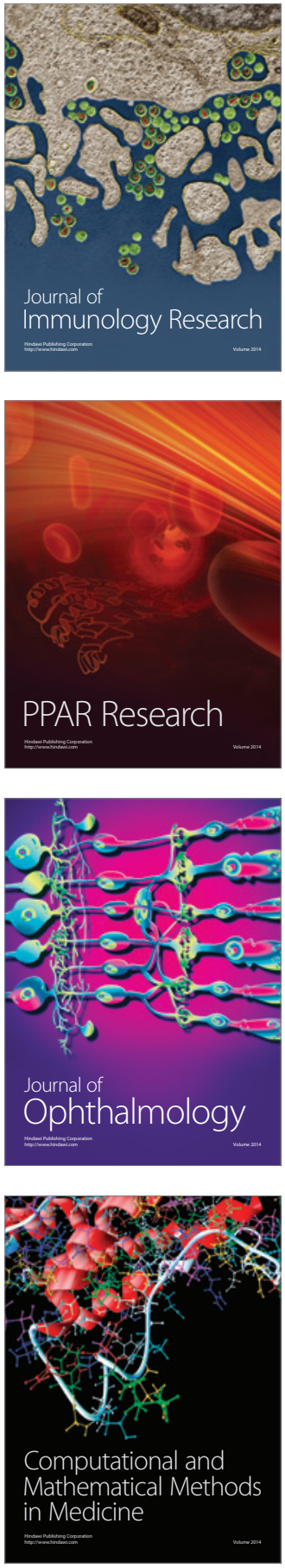

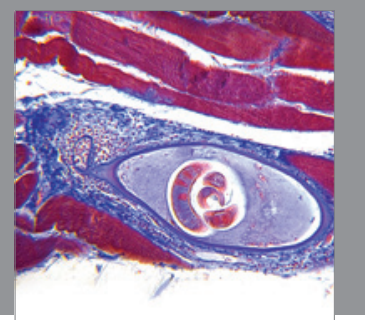

Gastroenterology

Research and Practice
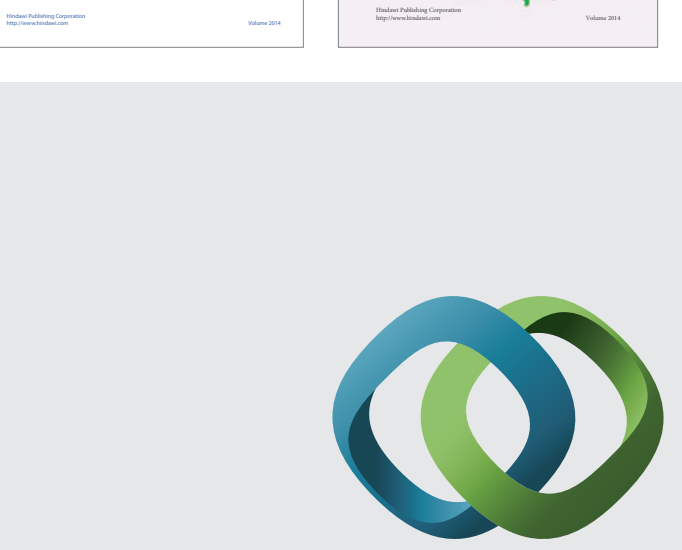

\section{Hindawi}

Submit your manuscripts at

http://www.hindawi.com
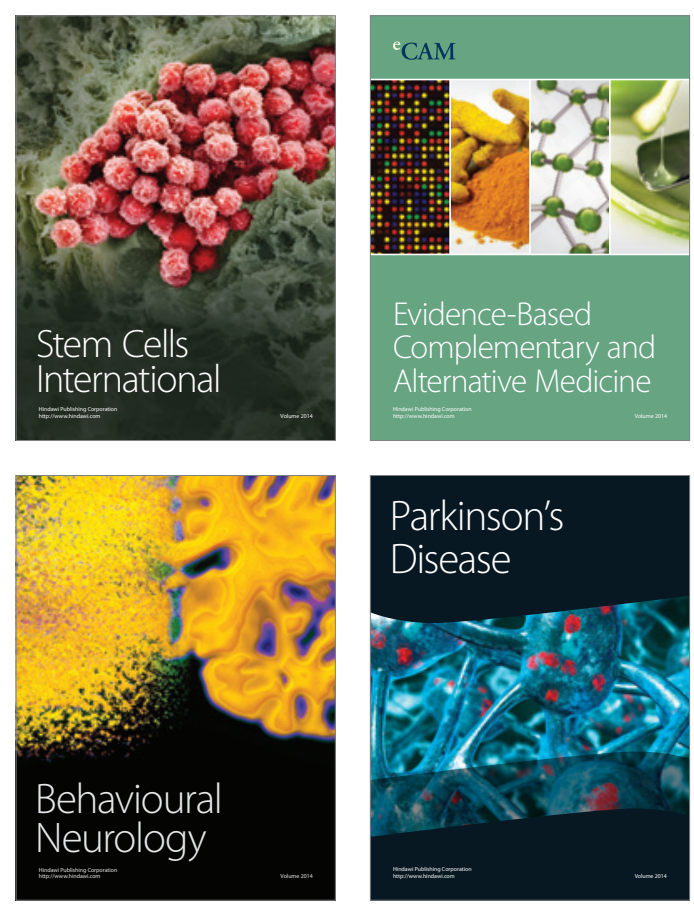

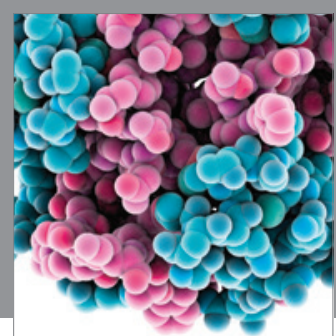

Journal of
Diabetes Research

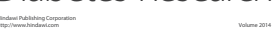

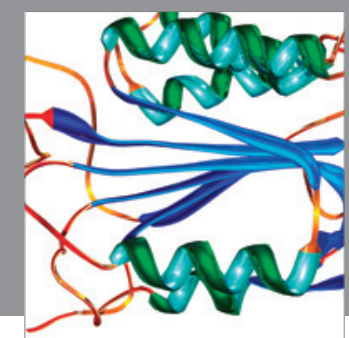

Disease Markers
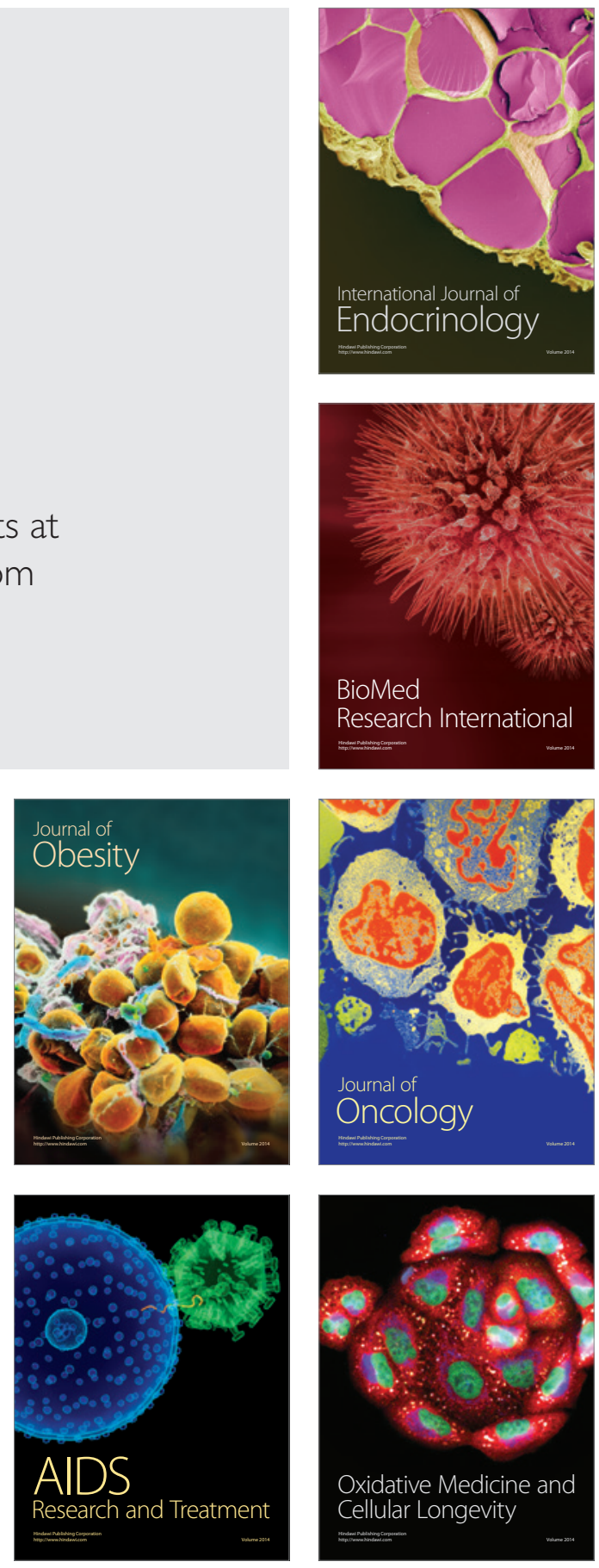